\title{
Dissimilaridade genética entre acessos de pimenta com potencial orna- mental
}

\author{
Raquel Silviana Neitzke ${ }^{1,4}$; Rosa Lía Barbieri'; Walter F Rodrigues ${ }^{3}$; Inez V Corrêa ${ }^{3}$; Fernando IF de \\ Carvalho ${ }^{2}$

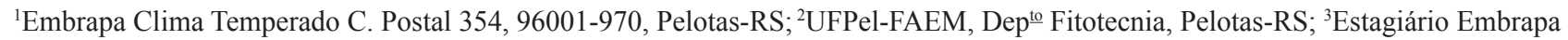 \\ Clima Temperado ${ }^{4}$ Estagiária e doutoranda em Agronomia, UFPel; raquelsilviana@gmail.com
}

\section{RESUMO}

Alguns tipos de pimentas do gênero Capsicum são utilizados como plantas ornamentais, por possuírem caracteres, que conferem valor estético, por serem de fácil cultivo e apresentarem grande durabilidade. Entretanto, no Brasil são poucas as variedades comerciais destinadas a este propósito. O presente trabalho teve por objetivo caracterizar e estudar a distância genética dos acessos com potencial ornamental do Banco Ativo de Germoplasma de Capsicum da Embrapa Clima Temperado. O experimento foi realizado de julho de 2007 a fevereiro de 2008, no campo experimental da Embrapa Clima Temperado, em blocos ao acaso, com três repetições, utilizando 17 acessos, com dez plantas por parcela. As plantas foram caracterizadas morfologicamente com oito descritores quantitativos e 22 descritores qualitativos. Foram realizadas análises de comparação de médias, variáveis canônicas, agrupamento pelo método UPGMA e de Tocher, para os dados quantitativos, e agrupamento pelo método UPGMA e de Tocher para os dados qualitativos. Os acessos foram agrupados de forma distinta quando utilizado dados quantitativos e dados qualitativos. A análise dos dados qualitativos separa mais os acessos, com a formação de maior número de grupos do que na análise dos dados quantitativos. A utilização conjunta da caracterização baseada em descritores quantitativos e qualitativos, porém com análises separadas, possibilita uma interpretação mais fidedigna da dissimilaridade genética e permite o melhor direcionamento dos cruzamentos em Capsicum.

Palavras-chave: Capsicum spp., banco ativo de germoplasma, caracterização morfológica, descritores quantitativos, descritores qualitativos.

\begin{abstract}
Genetic dissimilarity among pepper accessions with potential for ornamental use

Some plants of the Capsicum genus are used as ornamental plants because they have traits with aesthetic value, are easy to cultivate and have great durability. However, in Brazil there are few commercial varieties for this use. The goal of this work was to characterize and study genetic distance of accessions with ornamental potential from Capsicum Germplasm Bank of Embrapa Clima Temperado. The experiment was carried out from July 2007 to February 2008, at the experimental field of Embrapa Clima Temperado. The experimental design was randomized complete blocks, with three replicates, using 17 accessions. Ten plants per plot were used. Plants were morphologically characterized with eight quantitative descriptors and 22 qualitative descriptors. Quantitative data were used for analysis of means, canonical analysis, grouping by UPGMA and by Tocher methods. The qualitative data were grouped by UPGMA and by Tocher methods. The accessions were grouped in different ways when used quantitative and qualitative data. The analysis of qualitative data formed more groups than the analysis using quantitative data. The use of characterization based both on quantitative and on qualitative descriptors, but with separated analysis, allows a more reliable interpretation of genetic dissimilarity and indicates the best direction for crosses in Capsicum.
\end{abstract}

Keywords: Capsicum spp., germplasm bank, morphological characterization, quantitative descriptors, qualitative descriptors.

\section{(Recebido para publicação em 4 de novembro de 2008; aceito em 4 de janeiro de 2010) (Received on November 4, 2008; accepted on January 4, 2010)}

$\mathrm{O}$ processo de melhoramento genético é altamente dependente da amplitude da base genética disponível, que por sua vez é influenciada pelo acervo de recursos genéticos disponíveis, na forma de acessos coletados e caracterizados, mantidos nos bancos de germoplasma. A capacidade de acessar esses indivíduos, por coleta ou por intercâmbio, é fator fundamental para o sucesso de qualquer programa de melhoramento genético vegetal (Queiroz \& Lopes, 2007).

A falta ou a inadequação de informações sobre os acessos mantidos em bancos de germoplasma causa o baixo interesse dos melhoristas em relação aos acessos conservados (Barbieri, 2003). $\mathrm{O}$ incremento das atividades de caracterização e avaliação do germoplasma deve ser prioridade entre as estratégias de abordagem e manejo dos recursos genéticos no Brasil. Superadas as deficiências de informação, o germoplasma será mais útil para os programas de melhoramento.

A caracterização e a avaliação dos acessos proporcionam o melhor conhecimento do germoplasma disponível e permitem a identificação dos acessos duplicados, o estabelecimento de co- leções nucleares e a identificação dos modos de reprodução predominantes nos acessos, bem como da ocorrência ou não de variabilidade intrínseca em acessos individuais (Valls, 2007). A caracterização morfológica é um processo que, por meio da utilização de uma lista descritiva, trata de prover maiores informações sobre o germoplasma conservado, dispondo-o de uma forma mais efetiva para a utilização (Ramos et al., 1999).

As pimentas do gênero Capsicum se destacam como parte do mercado de hortaliças frescas no Brasil, bem como 
do forte segmento de condimentos, temperos e conservas em nível mundial (Bianchetti \& Carvalho, 2005). Capsicum possui cinco espécies domesticadas: C. annuum, C. baccatum, C. chinense, C. frutescens e C. pubescens (Pickersgill, 1997). Apresenta uma diversidade impressionante (Reifschneider, 2000), todavia, a diversidade do gênero foi pouco explorada e certamente não foi esgotada (Pickersgill, 1997).

Além do uso na culinária, alguns tipos de pimentas do gênero Capsicum são utilizados como plantas ornamentais, por possuírem caracteres que conferem valor estético, como folhagem variegada, pequeno porte, frutos de coloração intensa que contrastam com a folhagem (Carvalho et al., 2006), e também por serem de fácil cultivo e possuírem grande durabilidade. Um fator distintivo para uso ornamental é sua capacidade de crescer em recipientes como planta perene. No paisagismo, elas podem atingir um porte maior do que em vasos, principalmente se os vasos forem recipientes pequenos que limitam o crescimento radicular e aéreo. Cultivares ornamentais são usadas principalmente para decoração, mas os frutos podem ser usados para confecção de conservas ou serem desidratados (Witt, 1999).

No Brasil são poucas as variedades comerciais destinadas a este propósito, embora os bancos de germoplasma de Capsicum do país possuam em seu acervo acessos que podem ser utilizados no melhoramento genético com o objetivo de criar novas cultivares de pimentas ornamentais. Luz (2007) encontrou uma grande variabilidade entre acessos de Capsicum chinense avaliados por meio de descritores morfológicos e com potencial de uso desse germoplasma em programas de melhoramento. Sudré et al. (2005) publicaram um estudo de distância genética entre 56 acessos de pimenta e pimentão pertencentes à Coleção de Germoplasma de Capsicum da Universidade Estadual do Norte Fluminense utilizando técnicas multivariadas, onde sugeriram acessos para este fim. A Embrapa Clima Temperado mantém desde 2003 um Banco Ativo de Germoplasma de Capsicum, o qual conserva acessos de $C$. annuum, $C$. baccatum, $C$. chinense, $C$. frutescens $e$
C. pubescens.

O presente trabalho teve por objetivo caracterizar e estudar a distância genética dos acessos com potencial ornamental do Banco Ativo de Germoplasma de Capsicum da Embrapa Clima Temperado.

\section{MATERIAL E MÉTODOS}

Para a realização deste trabalho, foram escolhidos 17 acessos de pimenta que fazem parte do acervo do Banco Ativo de Germoplasma de Capsicum e que têm potencial ornamental para cultivo em vaso ou em jardim. Esta escolha foi baseada nos dados de passaporte dos acessos e em dados provenientes de caracterizações realizadas anteriormente. Os acessos utilizados no estudo de distância genética são variedades crioulas de C. annuum (P7, P22, P39, P51, P58, P77 e P119), C. baccatum (P3, P11, P14, P25, P28, P102 e P110), C. chinense (P66 e P78) e $C$. frutescens (P30), provenientes de coletas realizadas em feiras e de doações de agricultores.

A semeadura foi realizada em 27 de julho de 2007 em bandejas de poliestireno de 72 células preenchidas com substrato comercial. Em seis de outubro do mesmo ano, quando as mudas apresentaram de cinco a sete folhas verdadeiras, foram transplantadas para o campo experimental da Embrapa Clima Temperado. O delineamento experimental empregado foi blocos completos casualizados com 17 tratamentos (acessos) e três repetições. A unidade experimental foi composta por uma fileira com 10 plantas, no espaçamento de $0,5 \mathrm{~m}$ entre plantas e 1,2 m entre fileiras.

No período de dezembro de 2007 a fevereiro de 2008, quando as plantas apresentaram o primeiro fruto maduro, foi realizada a caracterização morfológica dos acessos. Foram utilizados oito descritores quantitativos (altura da planta, comprimento do dossel, comprimento da folha, largura da folha, comprimento do fruto, diâmetro do fruto, peso do fruto fresco e comprimento do pedúnculo) e 22 descritores qualitativos escolhidos entre os recomendados por Carvalho et al. (2003), conforme segue: 01) cor da haste: (1) verde; (2) verde com estrias violeta; (3) violeta; 02 ) antocianina nodal: (1) verde; (2) violeta claro; (3) violeta; (4) violeta escuro; 03) pubescência da haste: (1) esparsa; (2) intermediária; (3) densa; 04) hábito de crescimento da planta: (1) prostrado; (2) intermediário; (3) ereto; (4) outro; 05) densidade de ramificação: (1) esparsa; (2) intermediária; (3) densa; 06) brotação abaixo da primeira bifurcação: (1) ausente; (2) esparsa; (3) intermediária; (4) densa; 07) densidade de folhas: (1) esparsa; (2) intermediária; (3) densa; 08) cor da folha: (1) amarelo; (2) verde claro; (3) verde; (4) verde escuro; (5) violeta claro; (6) violeta; (7) variegada; (8) verde com antocianina; 09) pubescência da folha: (1) esparsa; (2) intermediária; (3) densa; 10) número de flores por axila: (1) uma; (2) duas; (3) três ou mais; (4) muitas com entrenó curto; (5) uma e duas; (6) uma, duas e três; (7) duas e três; (8) duas, três e quatro; 11) posição das flores na planta: (1) pendente; (2) intermediária; (3) ereta; (4) todas posições; (5) intermediária e ereta; (6) pendente e intermediária; 12) cor da corola: (1) branco; (2) amarelo claro; (3) amarelo; (4) amarelo esverdeado; (5) violeta com base branca; (6) branco com base violeta; (7) branco com margem violeta; (8) violeta; (9) branco esverdeado; (10) branco com mancha púrpura; (11) branco esverdeado com mancha púrpura; 13) cor da mancha na corola: (1) branco; (2) amarelo; (3) verde amarelado; (4) verde; (5) violeta; (6) sem mancha; 14) forma da corola: (1) rotada; (2) campanulada; (3) intermediária; 15) pigmento do cálice: (1) ausente; (2) presente; 16) cor do fruto imaturo: (1) branco; (2) amarelo; (3) verde; (4) laranja; (5) violeta; (6) violeta escuro; (7) amarelo esverdeado; (8) verde amarelado; (9) branco amarelado; (10) marrom. Quando o fruto apresenta mais de uma cor de fruto imaturo, é considerada a cor do primeiro estádio; 17) posição dos frutos na planta: (1) pendente; (2) intermediária; (3) ereta; (4) todas posições; (5) pendente e intermediária; (6) pendente e ereta; (7) intermediária e ereta; 18) cor do fruto maduro: (1) branco; (2) amarelo limão; (3) amarelo laranja pálido; (4) amarelo laranja; (5) laranja pálido; (6) laranja; (7) vermelho claro; (8) vermelho; (9) 
vermelho escuro; (10) violeta; (11) marrom; (12) preto; (13) amarelo; (14) amarelo pálido; 19) formato do fruto: (1) alongado; (2) arredondado; (3) triangular; (4) campanulado; (5) retangular; 20) formato da ponta do fruto: (1) pontiagudo; (2) truncado; (3) afundado; (4) afundado com ponta; 21) apêndice na ponta do fruto: (1) ausente; (2) presente; 22) superfície do fruto: (1) liso; (2) semi-rugoso; (3) rugoso; (4) liso com estrias; (5) semi-rugoso com estrias.

Todas as plantas da parcela experimental foram caracterizadas. Para os caracteres quantitativos foi considerada na análise a média da parcela experimental para cada descritor, sendo analisados cinco folhas e cinco frutos em cada planta para os descritores de folha e de fruto.

As médias obtidas foram agrupadas pelo critério de Scott \& Knott (1974). A estimativa da distância generalizada de Mahalanobis como medida de dissimilaridade foi aplicada para as análises do método de agrupamento das médias das distâncias (UPGMA) e no método de agrupamento de Tocher. Todas as análises estatísticas foram realizadas por meio do programa computacional Genes (Cruz, 2006). Na análise das variáveis canônicas, a divergência genética foi apresentada por meio de um gráfico cartesiano bidimensional de dispersão de escores. Foi construído um dendrograma pelo método UPGMA e calculado o coeficiente de correlação cofenética (r) (Sokal \& Rohlf, 1962), utilizando o programa computacional NTSYS pc 2.1 (Rohlf, 2000).

Para a complementação do estudo da distância genética entre os acessos foi realizada uma análise multicategórica. Para os descritores qualitativos, os dados foram obtidos por meio da moda de cada acesso para cada descritor. Os dados de caracteres qualitativos que apresentaram polimorfismo foram submetidos à análise de divergência genética pelo procedimento para dados multicategóricos do programa computacional Genes (Cruz, 2006). Esta metodologia consiste na obtenção de um índice, em que são considerados vários caracteres simultaneamente, sendo que cada caráter pode apresentar várias classes. A partir desta análise foi gerada uma matriz de dissimilaridade com base no complemento do coeficiente de coincidência simples, sendo esta empregada na formação do dendrograma pelo método UPGMA no programa computacional NTSYS pc 2.1 (Rohlf, 2000). A estimativa do ajuste de correlação do coeficiente cofenético entre a matriz de dissimilaridade e o dendrograma foi realizada no mesmo programa.

\section{RESULTADOS E DISCUSSÃO}

As médias apresentaram diferenças significativas entre si para todos os caracteres avaliados pela análise de variância. O teste de Scott e Knott (Scott \& Knott,1974) ao nível de significância de $5 \%$ de erro, agrupou as médias dos caracteres estudados (Tabela 1). O maior número de classes observado foi para

Tabela 1. Médias dos acessos de Capsicum com potencial ornamental em relação a oito caracteres quantitativos (means of Capsicum accessions with ornamental potential related to eight quantitative traits). Pelotas, UFPel, 2008.

\begin{tabular}{llcclllll}
\hline Acesso & AP (cm) & CD (cm) & CFO (cm) & LFO (cm) & CFR (cm) & DFR (cm) & PFF (g) & CP (cm) \\
\hline P3 & $71,87 \mathrm{a}$ & $105,93 \mathrm{a}$ & $10,50 \mathrm{c}$ & $4,17 \mathrm{~b}$ & $4,23 \mathrm{~d}$ & $1,97 \mathrm{~d}$ & $5,33 \mathrm{~d}$ & $4,70 \mathrm{a}$ \\
P7 & $40,07 \mathrm{~b}$ & $56,00 \mathrm{~d}$ & $6,20 \mathrm{~g}$ & $1,83 \mathrm{f}$ & $2,73 \mathrm{~h}$ & $2,10 \mathrm{~d}$ & $4,30 \mathrm{~d}$ & $2,43 \mathrm{f}$ \\
P11 & $69,70 \mathrm{a}$ & $99,00 \mathrm{a}$ & $12,43 \mathrm{a}$ & $4,67 \mathrm{a}$ & $5,17 \mathrm{c}$ & $0,9 \mathrm{~h}$ & $2,07 \mathrm{e}$ & $4,03 \mathrm{c}$ \\
P14 & $78,40 \mathrm{a}$ & $95,33 \mathrm{a}$ & $11,33 \mathrm{~b}$ & $3,87 \mathrm{c}$ & $5,07 \mathrm{c}$ & $5,63 \mathrm{a}$ & $28,3 \mathrm{a}$ & $4,50 \mathrm{~b}$ \\
P22 & $15,03 \mathrm{~d}$ & $19,07 \mathrm{f}$ & $6,80 \mathrm{f}$ & $1,73 \mathrm{f}$ & $3,37 \mathrm{f}$ & $1,20 \mathrm{~g}$ & $2,03 \mathrm{e}$ & $1,80 \mathrm{~h}$ \\
P25 & $44,13 \mathrm{~b}$ & $102,37 \mathrm{a}$ & $8,30 \mathrm{~d}$ & $3,53 \mathrm{~d}$ & $2,97 \mathrm{~g}$ & $2,87 \mathrm{~b}$ & $8,30 \mathrm{c}$ & $3,40 \mathrm{~d}$ \\
P28 & $57,23 \mathrm{a}$ & $81,33 \mathrm{~b}$ & $8,33 \mathrm{~d}$ & $3,50 \mathrm{~d}$ & $2,87 \mathrm{~g}$ & $2,90 \mathrm{~b}$ & $7,80 \mathrm{c}$ & $3,30 \mathrm{~d}$ \\
P30 & $65,97 \mathrm{a}$ & $81,33 \mathrm{~b}$ & $8,90 \mathrm{~d}$ & $3,83 \mathrm{c}$ & $3,00 \mathrm{~g}$ & $0,77 \mathrm{~h}$ & $0,90 \mathrm{e}$ & $2,67 \mathrm{f}$ \\
P39 & $29,30 \mathrm{c}$ & $60,53 \mathrm{~d}$ & $5,13 \mathrm{~h}$ & $1,70 \mathrm{f}$ & $1,40 \mathrm{j}$ & $1,40 \mathrm{f}$ & $1,67 \mathrm{e}$ & $1,50 \mathrm{i}$ \\
P51 & $59,80 \mathrm{a}$ & $71,97 \mathrm{~d}$ & $7,93 \mathrm{e}$ & $2,37 \mathrm{e}$ & $7,53 \mathrm{~b}$ & $1,03 \mathrm{~g}$ & $3,90 \mathrm{e}$ & $2,33 \mathrm{~g}$ \\
P58 & $30,83 \mathrm{c}$ & $36,17 \mathrm{e}$ & $7,67 \mathrm{e}$ & $2,43 \mathrm{e}$ & $8,40 \mathrm{a}$ & $2,73 \mathrm{c}$ & $17,7 \mathrm{~b}$ & $1,50 \mathrm{i}$ \\
P66 & $45,37 \mathrm{~b}$ & $86,73 \mathrm{~b}$ & $7,63 \mathrm{e}$ & $3,33 \mathrm{~d}$ & $3,57 \mathrm{e}$ & $1,77 \mathrm{~d}$ & $3,23 \mathrm{e}$ & $2,33 \mathrm{~g}$ \\
P77 & $47,97 \mathrm{~b}$ & $59,63 \mathrm{~d}$ & $8,30 \mathrm{~d}$ & $2,63 \mathrm{e}$ & $2,73 \mathrm{~h}$ & $1,93 \mathrm{~d}$ & $4,93 \mathrm{~d}$ & $2,50 \mathrm{f}$ \\
P78 & $45,00 \mathrm{~b}$ & $72,40 \mathrm{c}$ & $7,33 \mathrm{e}$ & $3,47 \mathrm{~d}$ & $3,20 \mathrm{f}$ & $1,67 \mathrm{e}$ & $2,43 \mathrm{e}$ & $1,93 \mathrm{~h}$ \\
P102 & $62,27 \mathrm{a}$ & $97,73 \mathrm{a}$ & $7,87 \mathrm{e}$ & $3,37 \mathrm{~d}$ & $2,77 \mathrm{~h}$ & $2,57 \mathrm{c}$ & $5,13 \mathrm{~d}$ & $3,07 \mathrm{e}$ \\
P110 & $63,40 \mathrm{a}$ & $84,87 \mathrm{~b}$ & $8,53 \mathrm{~d}$ & $3,80 \mathrm{c}$ & $2,30 \mathrm{i}$ & $1,90 \mathrm{~d}$ & $3,23 \mathrm{e}$ & $4,40 \mathrm{~b}$ \\
P119 & $52,20 \mathrm{a}$ & $68,40 \mathrm{c}$ & $5,27 \mathrm{~h}$ & $1,83 \mathrm{f}$ & $2,67 \mathrm{~h}$ & $1,03 \mathrm{~g}$ & $1,47 \mathrm{e}$ & $2,20 \mathrm{~g}$ \\
\hline CV (\%) & 16,73 & 6,41 & 3,93 & 4,93 & 3,81 & 7,06 & 21,61 & 5,15 \\
\hline
\end{tabular}

Médias seguidas pela mesma letra, em cada coluna, pertencem ao mesmo grupo pelo critério de Scott-Knott ao nível de 5\% de probabilidade de erro. $\mathrm{AP}=$ altura da planta; $\mathrm{CD}=$ comprimento do dossel; $\mathrm{CFO}=$ comprimento da folha; $\mathrm{LFO}=$ largura da folha; $\mathrm{CFR}=$ comprimento do fruto; $\mathrm{DFR}=$ diâmetro do fruto; $\mathrm{PFF}=$ peso do fruto fresco; $\mathrm{CP}=$ comprimento do pedúnculo (means followed by the same letter, in each column, do not differ significantly among them by the Scott-Knott test at $5 \%$ of probability of error. $\mathrm{AP}=$ plant height; $\mathrm{CD}=\mathrm{dossal}$ length; $\mathrm{CFO}=$ leaf length; $\mathrm{LFO}=$ leaf width; $\mathrm{CFR}=$ fruit length; $\mathrm{DFR}=$ fruit diameter; $\mathrm{PFF}=$ fresh fruit weight; $\mathrm{CP}=$ peduncle length). 
Tabela 2. Escores dos genótipos em relação às duas primeiras variáveis canônicas obtidas na avaliação da dissimilaridade genética em acessos de pimenta (scores of the genotypes according to two first canonical variables obtained in the evaluation of the genetic dissimilarity in pepper accessions). Pelotas, UFPel, 2008.

\begin{tabular}{lrr}
\hline \multirow{2}{*}{ Acesso } & \multicolumn{2}{c}{ Variáveis canônicas } \\
\cline { 2 - 3 } & $\mathbf{1}^{\circ}$ & $\mathbf{2}^{\circ}$ \\
\hline P3 & $-28,53$ & 61,21 \\
P7 & $-10,15$ & 40,34 \\
P11 & $-16,39$ & 62,01 \\
P14 & $-29,49$ & 77,95 \\
P22 & 3,78 & 36,46 \\
P25 & $-30,36$ & 49,93 \\
P28 & $-31,80$ & 49,36 \\
P30 & $-23,05$ & 41,73 \\
P39 & $-15,23$ & 27,94 \\
P51 & 43,81 & 55,41 \\
P58 & 52,31 & 56,76 \\
P66 & $-11,41$ & 42,56 \\
P77 & $-18,93$ & 44,36 \\
P78 & $-14,11$ & 37,84 \\
P102 & $-28,49$ & 47,21 \\
P110 & $-44,30$ & 48,29 \\
P119 & $-5,11$ & 34,22 \\
\hline Variância (\%) & 74,77 & 22,08 \\
Variância acumulada (\%) & 74,77 & 96,85 \\
\hline
\end{tabular}

o caráter comprimento do fruto, que evidenciou dez classes distintas, com as médias variando de $1,40 \mathrm{~cm}$ (P39) a 8,40 $\mathrm{cm}$ (P58). O caráter que menos demonstrou classes foi a altura da planta, com quatro classes diferentes e valores médios variando de $15,03 \mathrm{~cm}$ (P22) a 78,40 $\mathrm{cm}(\mathrm{P} 14)$. O grande número de classes que foi estabelecido é um indicativo da grande variabilidade existente entre os acessos com potencial ornamental.

A distância média de Mahalanobis entre os acessos $\left(D^{2}=1601,22\right)$ foi utilizada como critério para a formação dos grupos. No dendrograma houve a formação de três grupos, o primeiro formado pela grande maioria dos acessos $(\mathrm{P} 3, \mathrm{P} 7$, P11, P22, P25, P28, P30, P39, P66, P77, P78, P102, P110 e P119), o segundo formado exclusivamente pelo acesso P14 e o terceiro pelos acessos P51 e P58 (Figura 1). O acesso P14 se destaca em relação aos demais por possuir a maior altura da planta, maior diâmetro de fruto $(5,63 \mathrm{~cm})$ e o maior peso de fruto $(28,27$ g). Os acessos P51 e P58 são os que possuem os maiores valores para comprimento do fruto, com 7,53 cm e 8,4 $\mathrm{cm}$, respectivamente. A alta correlação cofenética $(0,91)$ mostra a consistência da análise de agrupamento em relação à matriz de dissimilaridade.

Conforme Cruz \& Regazzi (1994), para uma interpretação satisfatória da variabilidade manifestada entre genótipos é necessário que as duas primeiras variáveis canônicas permitam uma estimativa mínima de $80 \%$ da variação total contida no conjunto de caracteres. Neste trabalho as duas primeiras variáveis canônicas explicaram cerca de 96,85\% da variação (Tabela 2).

Com esses resultados foi possível a construção de um gráfico, de dispersão para a visualização bidimensional, dos genótipos analisados, utilizando os escores da primeira e da segunda variável canônica (Figura 2). A dispersão gráfica permitiu a separação dos acessos em grupos, podendo ser utilizada como uma estratégia para selecionar genótipos divergentes a serem utilizados em cruzamentos artificiais.

Dois grupos principais foram estabelecidos pelo dendrograma, sendo o primeiro composto pelos acessos $\mathrm{P} 3$, P7, P11, P14, P22, P25, P28, P30, P39, P66, P77, P78, P102, P110 e P119 e o segundo pelos acessos P51 e P58. Os resultados são concordantes parcialmente com o dendrograma gerado (Figura 1), onde os acessos P51 e P58 ficaram isolados dos demais em ambos os métodos de agrupamento, porém na dispersão gráfica o acesso P14 não ficou separado da grande maioria dos acessos.

A estimativa das distâncias genéticas permitiu a formação de quatro grupos distintos pelo método de Tocher para os descritores quantitativos. O primeiro grupo reuniu a grande maioria dos acessos (P3, P7, P11, P25, P28, P30, P39, P66, P77, P78, P102, P110 e P119), o segundo foi formado pelos acessos P51 e P58, o terceiro e o quarto somente por um acesso em cada grupo, P22 e P14, respectivamente. $\mathrm{O}$ acesso $\mathrm{P} 22$ possui a menor altura $(15,03 \mathrm{~cm})$ e o menor comprimento do dossel $(19,07 \mathrm{~cm})$ de todos os que foram caracterizados. Genótipos de pequeno porte são bastante desejáveis para uso ornamental, pois possibilitam o cultivo em recipientes relativamente pequenos sem comprometer o crescimento e desenvolvimento da planta. Genótipos de porte mediano a alto podem ser destinados ao paisagismo, para cultivo em jardins.

A formação dos grupos nos métodos utilizados não possibilitou a separação entre as espécies de Capsicum, onde o primeiro grupo, em todas as análises, possui exemplares das quatro espécies utilizadas no estudo, C. annuum, C. baccatum, C.chinense e $C$. frutescens.

Para complementação dos dados e uma caracterização mais detalhada foi realizada a análise de dissimilaridade por meio de descritores qualitativos. Estes descritores são muito importantes para a identificação dos acessos com maior potencial ornamental, assim como para utilizar em cruzamentos para obtenção de cultivares ornamentais de pimenta. Os descritores qualitativos mais importantes para avaliação do potencial ornamental, em relação ao aspecto estético, são coloração dos frutos quando imaturos e maduros, 


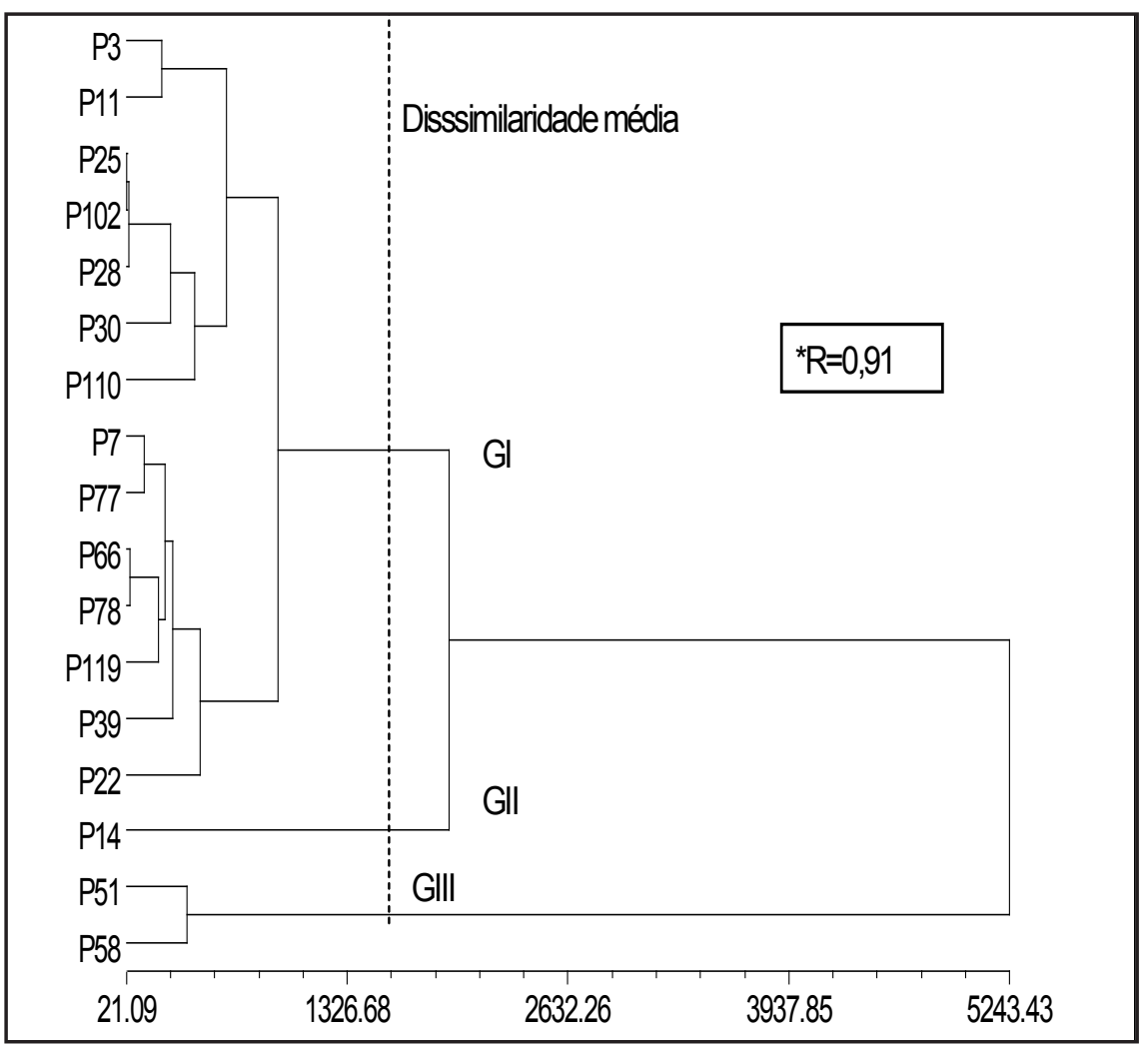

Figura 1. Dendrograma de análise de agrupamento de 17 acessos de pimentas do gênero Capsicum pelo método UPGMA, utilizando a distância de Mahalanobis, obtido a partir da análise de caracteres quantitativos. *R: Correlação cofenética (dendrogram resulting from grouping analysis by the UPGMA method of 17 pepper accessions of Capsicum genus, using Mahalanobis distance, obtained from quantitative traits analyses. *R: Cophenetical correlation). Pelotas, UFPel, 2008.

posição dos frutos na planta, hábito de crescimento da planta, densidade de ramificação, densidade de folhas, cor das folhas e formato dos frutos. De modo geral, os acessos de Capsicum estudados revelaram diferenças para todos os descritores utilizados, com exceção do descritor presença de apêndice na ponta do fruto, para o qual todos os acessos apresentaram ausência do mesmo, sendo desta forma descartado da análise de divergência genética.

O dendrograma resultante da análise de agrupamento pelo método UPGMA (Figura 3) utilizando dados qualitativos revelou a formação de seis grupos pelo corte na dissimilaridade média entre os acessos estudados $(0,480)$. O primeiro grupo reuniu os acessos P3, P14, P22, P51, P58. Estes acessos foram monomórficos para os seguintes descritores: hábito de crescimento (intermediário), brotação abaixo da primeira bifurcação (esparsa), número de flores por axila (uma), pigmento do cálice (ausente) folhas, corola e nos frutos imaturos, o que permite indicá-lo como acesso ornamental.

Pelo método de Tocher, usando os dados qualitativos, houve a formação de oito grupos distintos: Grupo 1 (P11, P25, P28, P102 e P119), Grupo 2 (P3, P22, P51 e P58), Grupo 3 (P7 e P39), Grupo 4 (P66 e P78), Grupo 5 (P30), Grupo 6 (P14), Grupo 7 (P77) e Grupo 8 (P110). $\mathrm{O}$ agrupamento de Tocher utilizando dados quantitativos foi diferente do agrupamento utilizando dados qualitativos. $\mathrm{Na}$ análise de dados quantitativos houve a formação de quatro grupos. O único grupo, inalterado nas duas análises, foi aquele composto pelo acesso P14. Bento et al. (2007), no estudo da variabilidade fenotípica entre 29 acessos de pimenta, também obtiveram diferenças em relação ao número de grupos formados pelo método de Tocher usando dados quantitativos e qualitativos, com dois e sete grupos, respectivamente.

A identificação de genótipos com base somente na divergência genética, sem considerar seus próprios desempenhos, pode não ser uma boa estratégia em programas de melhoramento (Carpentieri-Pípolo et al., 2000). Por isso, além dos dados resultantes da análise de divergência genética, os acessos devem ser recomendados com base no aspecto ornamental. Embora seja uma forma subjetiva de ajudar na seleção dos genótipos para o melhoramento, pode contribuir muito para o sucesso do mesmo.

Para o melhoramento, são recomendados cruzamentos entre acessos pertencentes à mesma espécie de Capsicum, que possuem caracteres altamente desejáveis para uso ornamental e com maior dissimilaridade genética. Embora seja possível realizar cruzamentos interespecíficos, é mais fácil a obtenção de sucesso em cruzamentos com plantas da mesma espécie.

Os resultados obtidos no presente trabalho evidenciam que os acessos de C. annuum com caracteres mais adequados ao uso ornamental e mais recomendados para o melhoramento genético são P7, P22, P39, P58, P77 e P119. Os acessos P22, P39 e P58 apresentam plantas com pequena altura e caracteres qualitativos desejáveis. As 


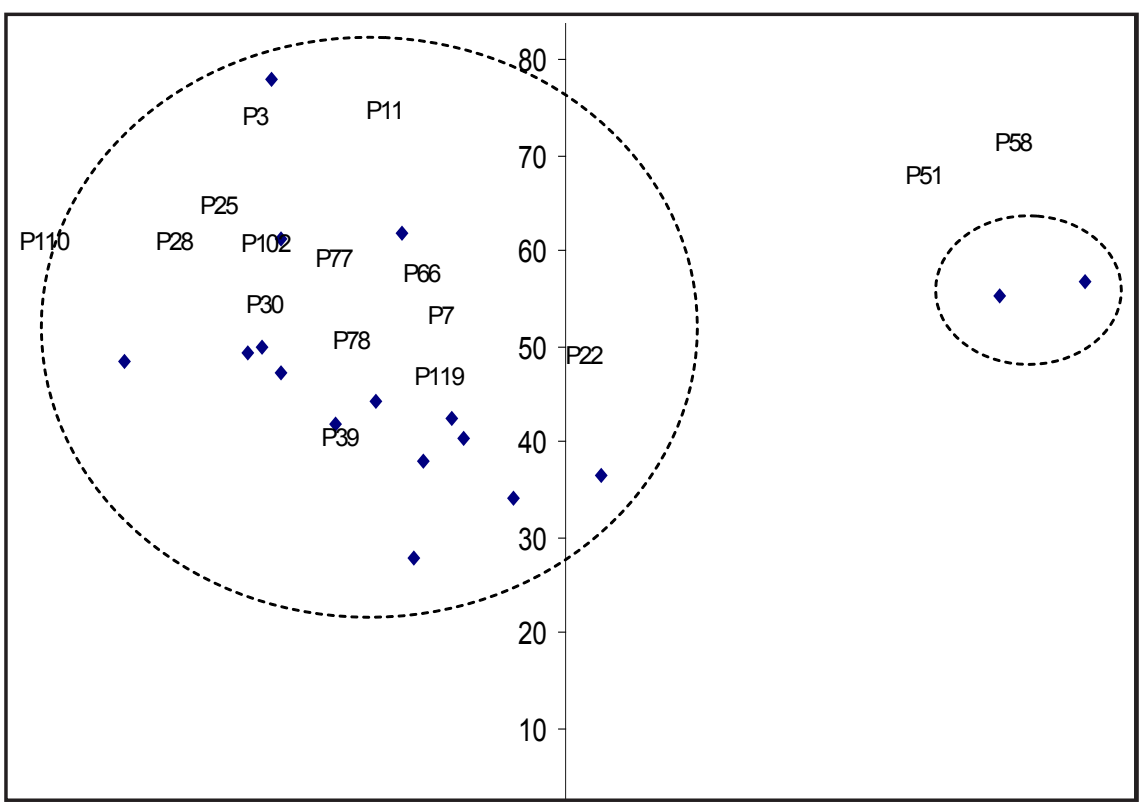

Figura 2. Gráfico de dispersão de 17 acessos de Capsicum, considerando as duas primeiras variáveis canônicas (graphical dispersion of 17 Capsicum accessions, considering the two first canonical variables). Pelotas, UFPel 2008.

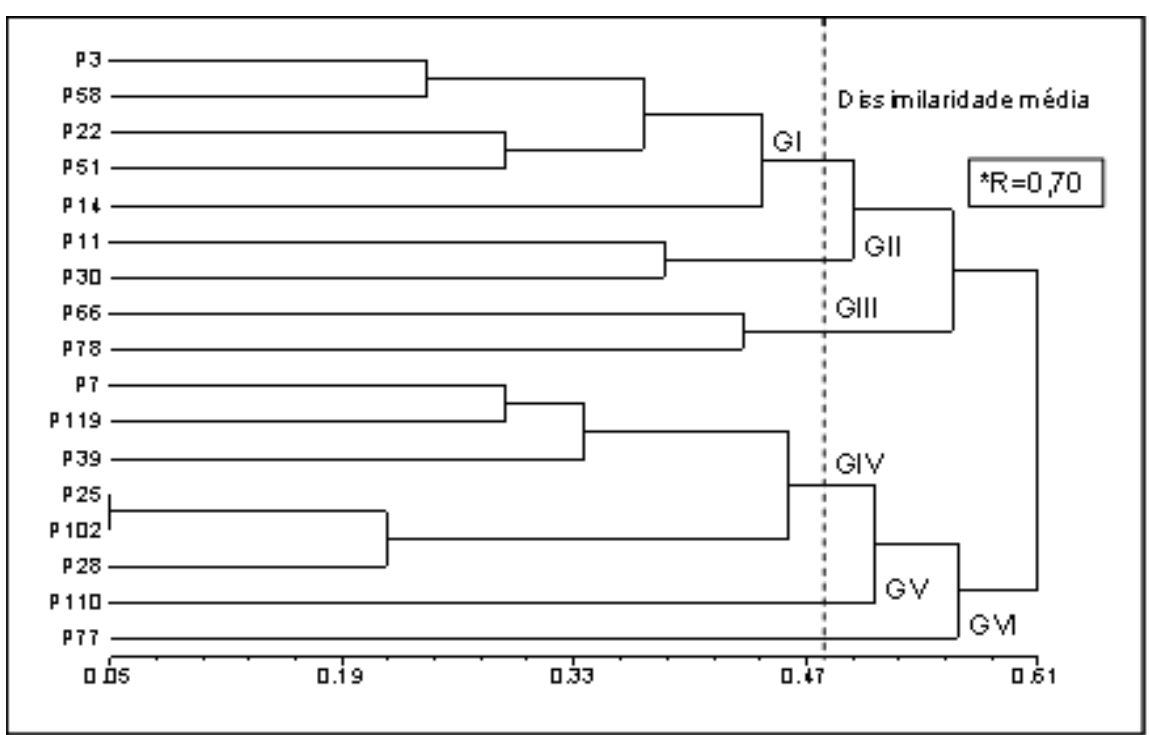

Figura 3. Dendrograma de análise de agrupamento de 17 acessos de pimentas do gênero Capsicum pelo método UPGMA, utilizando complemento do índice de coincidência simples como medida de distância genética, obtido a partir da análise dos dados qualitativos. ${ }^{*} \mathrm{R}$ : Correlação cofenética (dendrogram resulting from grouping analysis by UPGMA analysis of 17 pepper accessions from Capsicum genes, using complement of simple agreement index as a measurement of genetic distance, obtained from analysis of qualitative data. ${ }^{*} \mathrm{R}$ : Cophenetical correlation). Pelotas, UFPel, 2008.

plantas dos acessos P7 e P119 possuem altura mediana, entretanto, a passagem por diversas cores dos frutos no processo de maturação favorece seu uso no melhoramento. P77, por apresentar intensa coloração violeta nas folhas, nas hastes, nos frutos imaturos e nas flores, é bastante distinto dos demais.
Os acessos de C. baccatum que apresentaram características mais indicadas para serem usados no melhoramento de pimenta ornamental são P25, P28, P102 e P110. É recomendado o uso do acesso P110 como genitor em cruzamentos com P25, P28 ou P102. Não é indicado o cruzamento entre P25, P28 e P102, pois estes apresentam baixa dissimilaridade genética entre si. Os acessos $\mathrm{P} 25$, P28, P102 e P110 possuem um porte relativamente alto, sendo necessária a realização de seleção com a finalidade de diminuir o porte da planta para cultivo em vaso. No entanto estes acessos podem ser perfeitamente utilizados para melhoramento de cultivares para uso em paisagismo.

Os acessos de $C$. chinense avaliados (P66 e P78), embora possuam porte relativamente baixo, não são muito promissores para o uso ornamental, pois possuem frutos pendentes que ficam escondidos sob as folhas, o que impede sua visualização. Podem ser cruzados com outros genótipos para incorporar caracteres que aumentem seu valor estético como: posição ereta dos frutos e a presença de um maior número de cores durante o processo de maturação do fruto.

$\mathrm{O}$ acesso $\mathrm{P} 30$ (C. frutescens) é muito interessante para cultivo em jardim, por apresentar um grande número de frutos de coloração vermelha intensa quando maduros, com posição ereta que contrastam com a folhagem.

Os acessos de pequeno porte podem tanto ser cultivados em jardim quanto em vasos, mas os de porte mais alto são recomendados principalmente para cultivo em jardim. As pimentas do gênero Capsicum podem ser exploradas para o cultivo em jardins funcionais, como jardins de temperos, jardins de plantas medicinais e jardins aromáticos.

Existe dissimilaridade genética entre os acessos de Capsicum estudados, evidenciada mediante a análise de caracteres quantitativos e qualitativos, e esta pode ser explorada para compor blocos de cruzamentos em programas de melhoramento genético com objetivo de desenvolver cultivares ornamentais de pimentas.

A análise dos dados qualitativos separa mais os acessos, com a formação de maior número de grupos do que na análise dos dados quantitativos.

A caracterização baseada em descritores quantitativos e a caracterização baseada em descritores qualitativos fornecem dados que possibilitam uma interpretação fidedigna da dissimilaridade genética e permitem o melhor 
direcionamento dos cruzamentos em Capsicum em programas de melhoramento de pimentas ornamentais.

\section{AGRADECIMENTOS}

Ao CNPq pela concessão da bolsa de doutorado ao primeiro autor e à Embrapa Clima Temperado, pelo fornecimento de toda a infra-estrutura necessária para a execução do trabalho.

\section{REFERÊNCIAS}

BARBIERI RL. 2003. Conservação e uso de recursos genéticos vegetais. In: FREITAS LB; BERED F (eds). Genética e evolução vegetal. Porto Alegre: UFRGS. p. 403-413.

BENTO CS; SUDRÉ CP; RODRIGUES R; RIVA EM; PEREIRA MG. 2007. Descritores qualitativos e multicategóricos na estimativa da variabilidade fenotípica entre acessos de pimenta. Scientia Agraria 8: 149-156.

BIANCHETTI L; CARVALHO SIC. 2005. Subsídios à coleta de germoplasma de pimentas e pimentões do gênero Capsicum (Solanaceae). In: WALTER BMT; CAVALCANTI TB. (eds). Fundamentos para coleta de germoplasma vegetal. Brasília: Embrapa Recursos Genéticos e Biotecnologia. p. 355-385.

CARPENTIERI-PÍPOLO V; DESTRO C; PRETE CEC; GONZALES MGN; POPPER
I; ZANATTA S; SILVA FAM. 2000. Seleção de genótipos parentais de acerola com base na divergência genética multivariada. Pesquisa Agropecuária Brasileira 8: 1613-1619.

CARVALHO SIC; BIANCHETTI LB; BUSTAMANTE PG; SILVA DB. 2003. Catálogo de germoplasma de pimentas e pimentões (Capsicum spp.) da Embrapa Hortaliças. Brasília: Embrapa Hortaliças. 49p. (Documentos, 49)

CARVALHO SIC; BIANCHETTI LB; RIBEIRO CSC; LOPES CA. 2006. Pimentas do gênero Capsicum no Brasil. Brasília: Embrapa Hortaliças. 27p. (Documentos, 94).

CRUZ CD. 2006. Programa Genes (versão Windows): aplicativo computacional em genética e estatística. Viçosa: UFV, 175p.

CRUZ CD; REGAZZI AJ. 1994. Modelos biométricos aplicados ao melhoramento genético. Viçosa: UFV. 390p.

LUZ FJF. 2007. Caracterização morfológica e molecular de acessos de pimenta (Capsicum chinense Jaqc). Jaboticabal: UNESP. 70p. (Tese doutorado).

PICKERSGILL B. 1997. Genetic resources and breeding of Capsicum spp. Euphytica 96: 129-133.

QUEIROZ MA; LOPES MA. 2007. Importância dos recursos genéticos para o agronegócio. In: NASS LL. (ed.) Recursos genéticos vegetais. Brasília: Embrapa Recursos Genéticos e Biotecnologia. p. 281-305.

RAMOS SRR; QUEIRÓZ MA; CASALI VWD; CRUZ CD. 1999. Recursos genéticos de Cucurbita moschata: caracterização morfológica de populações locais coletadas no Nordeste brasileiro. In: QUEIRÓZ MA; GOEDERT CO; RAMOS SRR (ed.). Recursos genéticos e melhoramento de plantas para o Nordeste brasileiro. (on line). Versão 1.0. Petrolina-PE: Embrapa Semi-Árido, Brasília-DF: Embrapa Recursos Genéticos e Biotecnologia, Disponível em www.cpatsa. embrapa.br.

REIFSCHNEIDER FJB. (ed). 2000. Capsicum: pimentas e pimentões no Brasil. Brasília: Embrapa Comunicação para Transferência de Tecnologia/Embrapa Hortaliças. 113p.

ROHLF FJ. 2000. NTSYS-pc: numerical taxonomy and multivariate analysis system, version 2.1. New York: Exeter Software.

SCOTT AJ; KNOTT MA. 1974. Cluster analysis methods for grouping means in the analysis of variance. Biometrics 30: 507-512.

SOKAL RR; ROHLF FJ. 1962. The comparison of dendrograms by objective methods. Taxon 11: 30-40.

SUDRÉ CP; RODRIGUES R; RIVA EM; KARASAWA M; AMARAL JÚNIOR AT. 2005. Divergência genética entre acessos de pimenta e pimentão utilizando técnicas multivariadas. Horticultura Brasileira 23: 22-27.

VALLS JFM. 2007. Caracterização de Recursos Genéticos Vegetais. In: NASS LL (Ed.) Recursos genéticos vegetais. Brasília: Embrapa Recursos Genéticos e Biotecnologia. p. 281305.

WITT D. 1999. The chile pepper encyclopedia. New York: William Morrow and Company, $337 \mathrm{p}$. 